\title{
ARTICLE \\ Opposing effects of an atypical glycinergic and substance $P$ transmission on interpeduncular nucleus plasticity
}

\author{
Riccardo Melani ${ }^{1}$, Richard Von Itter ${ }^{1}$, Deqiang Jing ${ }^{2}$, Peter Koppensteiner ${ }^{1}$ and Ipe Ninan (iD
}

The medial habenula-interpeduncular nucleus (MHb-IPN) pathway has recently been implicated in the suppression of fear memory. A notable feature of this pathway is the corelease of neurotransmitters and neuropeptides from MHb neurons. Our studies in mice reveal that an activation of substance P-positive dorsomedial habenula ( $\mathrm{dMHb}$ ) neurons results in simultaneous release of glutamate and glycine in the lateral interpeduncular nucleus (LIPN). This glycine receptor activity inhibits an activity-dependent long-lasting potentiation of glutamatergic synapses in LIPN neurons, while substance $P$ enhances this plasticity. An endocannabinoid $C B 1$ receptor-mediated suppression of $G A B A_{B}$ receptor activity allows substance $P$ to induce a long-lasting increase in glutamate release in LIPN neurons. Consistent with the substance P-dependent synaptic potentiation in the LIPN, the NK1R in the IPN is involved in fear extinction but not fear conditioning. Thus, our study describes a novel plasticity mechanism in the LIPN and a region-specific role of substance $P$ in fear extinction.

Neuropsychopharmacology (2019) 44:1828-1836; https://doi.org/10.1038/s41386-019-0396-6

\section{INTRODUCTION}

The medial habenula (MHb)-interpeduncular nucleus (IPN) pathway is a major component of the dorsal diencephalic conduction system and it acts as a link between the forebrain and the midbrain [1]. Apart from the well-established role of the MHb-IPN pathway in nicotine addiction [2], the emerging data suggest an important role for the MHb-IPN synapses in fear suppression [3-5]. The $\mathrm{MHb}$ is subdivided into dorsal (dMHb) and ventral (vMHb) nuclei [6-10]. The choline-acetyltransferase-positive vMHb neurons project to the central interpeduncular nucleus (CIPN), while the substance P-positive $\mathrm{dMHb}$ neurons project to the lateral interpeduncular nucleus (LIPN) [11] (Fig. 1a). Recent studies have shown that a potentiation of either glutamatergic or cholinergic transmission in the vMHb-CIPN pathway leads to a suppression of fear memory $[3,4]$. Consistently, we observed a bidirectional regulation of $\mathrm{vMHb}-\mathrm{CIPN}$ plasticity by fear conditioning and extinction, i.e., fear conditioning suppressed an activity-dependent synaptic potentiation at the vMHb-CIPN glutamatergic synapses, while fear extinction reversed this deficit [5]. Although the unique features of the vMHb-CIPN synapses, including the excitatory effects of $G A B A_{B}$ receptors, the selective effect of $C B 1$ receptor modulation on acetylcholine release, and how these exceptional properties influence fear suppression have been documented [3-5], little is known about plasticity at the dMHb-LIPN synapses or its functional significance.

A major feature of the MHb-IPN synapses is the corelease of neurotransmitters and neuropeptides from $\mathrm{MHb}$ neurons [4, 12]. The corelease of the classical small-molecule and neuropeptide transmitters could produce a combination of ionotropic and metabotropic signaling to elicit optimal synaptic plasticity and hence modulate behavior [13]. Although the glutamatergic $\mathrm{dMHb}$ neurons express abundant levels of substance $P[8,11]$, the action of substance $P$ on its target neurons in the LIPN or its behavioral relevance is unknown. Substance $P$ has been called a "pioneering neuropeptide" because of its role in providing important insights into the properties and actions of other neuropeptides [14]. Past studies have indicated the role of substance $P$ in synaptic plasticity [15]. Given the robust expression of substance $\mathrm{P}$ in $\mathrm{dMHb}$ neurons $[8,11]$, it is important to understand whether and how substance $P$ corelease modulates the dMHb-LIPN synapses. The NK1 receptor, the primary receptor for substance $P$, signals through phospholipase $C$ (PLC) leading to an increase in intracellular $\mathrm{Ca}^{2+}$ [16]. The corelease of substance $P$ could influence the ability of $\mathrm{dMHb}$-LIPN synapses to undergo plasticity. Furthermore, the dMHb-LIPN pathway shows an ample expression of cannabinoid $C B 1, G A B A_{B}$, and glycine receptors, which might play a role in $\mathrm{dMHb}-$ LIPN synaptic transmission and plasticity [3, 17-21].

Our current study revealed that an activation of $\mathrm{dMHb}$ neurons results in a simultaneous activation of glutamatergic and glycinergic receptors in the LIPN. Furthermore, glycinergic transmission suppresses activity-dependent synaptic potentiation in LIPN neurons, while substance $P$ enhances this plasticity via a $C B 1$ - and $\mathrm{GABA}_{\mathrm{B}}$ receptor-dependent manner.

\section{MATERIALS AND METHODS}

Animals

An average of 2-4 months old male mice were used. C56BL/6J mice, Tac1-ChR2-EYFP mice [generated by crossing homozygous B6;129S-Tac1tm1.1(cre)Hze/J and homozygous B6.Cg-Gt(ROSA) 26Sortm32(CAG-COP4*H134R/EYFP)Hze/J mice], GAD67-GFP, and PV-tdTomato mice [generated by crossing homozygous B6;129P2Pvalbtm1(cre)Arbr/J and B6;129S6-Gt(ROSA)26Sortm14(CAG-tdTomato)Hze/J mice] were originally obtained from Jackson

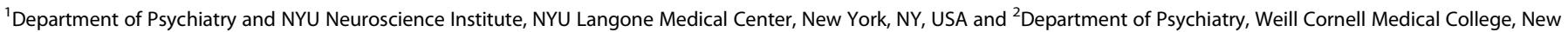
York, NY, USA

Correspondence: Ipe Ninan (Ipe.Ninan@nyumc.org)

Received: 15 March 2019 Revised: 10 April 2019 Accepted: 15 April 2019

Published online: 20 April 2019 
A

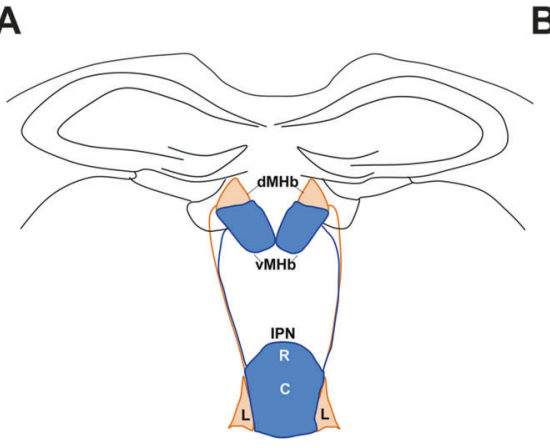

B

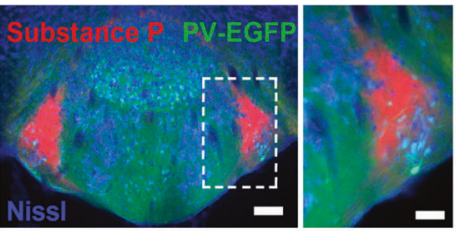

C
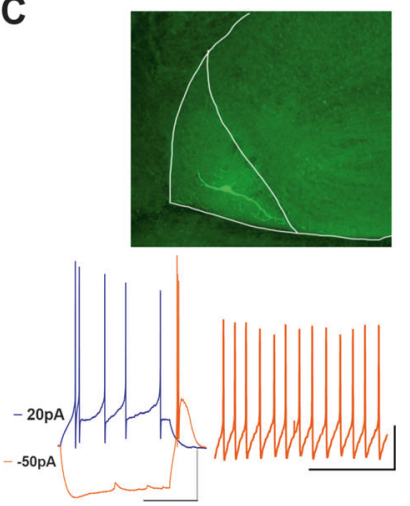

D
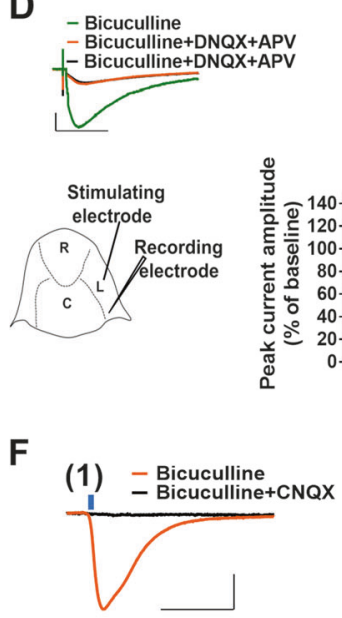

- Bicuculline Bicuculline+DNQX+APV - Bicuculline+DNQX+APV+strychnine 

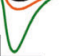

DNQX+APY Bicuculline

\section{DNQX+APV Bicuculline}

Strychnine
(3)

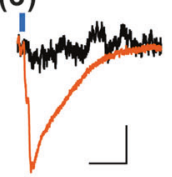

$\mathbf{F}$
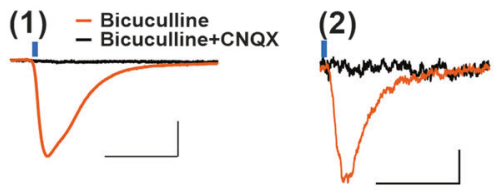

(4)

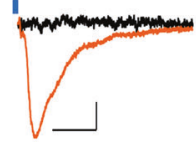

E

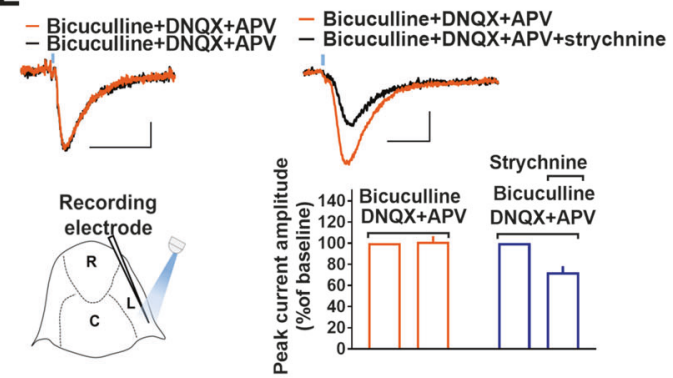

G

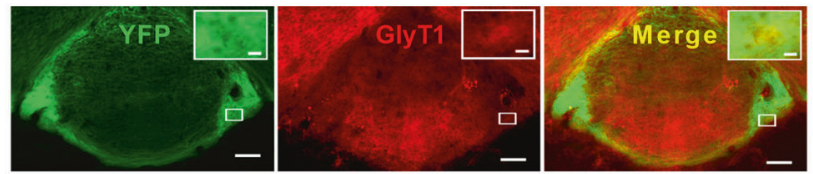

H

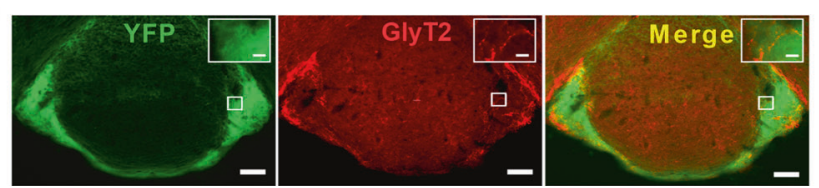

Fig. 1 Synaptic transmission in LIPN neurons. a A schematic presentation of the MHb-IPN pathway. dMHb-dorsomedial habenula; vMHbventromedial habenula; IPN-interpeduncular nucleus; R-rostral; C-central; L-lateral. b Expression of substance P in the LIPN of mice expressing EGFP in PV neurons (GAD67-GFP mice). Scale 100/50 (inset) $\mu$ m. c Upper panel shows a confocal image of biocytin filled LIPN neuron. Lower left panel shows voltage responses to hyperpolarizing $(-50 \mathrm{pA})$ and depolarizing $(+20 \mathrm{pA})$ current steps in LIPN neurons. Scale bar, $20 \mathrm{mV} / 0.5 \mathrm{~s}$. Lower right panel shows an example trace of spontaneous action potentials in LIPN neurons. Scale bar, $20 \mathrm{mV} / 0.5 \mathrm{~s}$. d Field stimulation in the LIPN produces both glutamatergic and glycinergic transmission. Left panel shows schematic presentation of the positions of stimulating and recording electrodes in the LIPN. Blue bars show average current amplitude before the application of DNQX/APV cocktail (0-5 min of the experiment), after 10-15 min perfusion of DNQX/APV cocktail (15-20 min of the experiment) and after 10-15 min perfusion strychnine in the presence of DNQX/APV cocktail (30-35 min of the experiment) ( $n=9$ neurons/5 mice). Orange bars show average current amplitude at same time points in parallel control experiments (without strychnine, $n=7$ neurons/4 mice). Bicuculline was present throughout the experiment. Upper panel shows example traces. Scale, $50 \mathrm{pA} / 10 \mathrm{~ms}$ (traces for orange bars), $200 \mathrm{pA} / 10 \mathrm{~ms}$ (traces for blue bars). e Optogenetic activation of dMHb terminals in Tac1-ChR2-EYFP mice produces both the glutamatergic and glycinergic responses in LIPN neurons. Left panel shows schematic presentation of light-evoked current recording in LIPN neurons. Blue bars show average current amplitude before and $15 \mathrm{~min}$ after the application of strychnine ( $n=11$ neurons/6 mice). Bicuculline, DNQX, and APV were present throughout the experiment. Orange bars show average current amplitude in parallel control experiments in the presence of bicuculline, DNQX, and APV ( $n=10$ neurons/7 mice). Upper panel shows example traces. Scale, $20 \mathrm{pA} / 10 \mathrm{~ms}$. Blue line indicates light activation. $\mathbf{f}$ The residual current after the blockade of $\mathrm{GABA}_{\mathrm{A}}$ receptors is abolished by CNQX at $100 \mu \mathrm{M}$ concentration. Scale, $100 \mathrm{pA} /$ $25 \mathrm{~ms}$ (Neuron 1), Scale, $10 \mathrm{pA} / 25 \mathrm{~ms}$ (Neurons 2, 3, and 4). Blue line indicates light activation. $\mathbf{g}, \mathbf{h}$ GlyT1 and GlyT2 expression in the LIPN. Scale 100/12.5 (inset) $\mu \mathrm{m}$

Laboratory. All procedures were approved by the Institutional Animal Care and Use Committee of the New York University School of Medicine.

\section{Immunohistochemistry}

Immunohistochemistry was carried out as described recently [22]. Slices were incubated with primary antibodies [antiglycine transporter 1, polyclonal rabbit, 1:1000 (Synaptic Systems, RRID: $\left.A B \_2713969\right)$, antiglycine transporter 2 polyclonal guinea Pig, 1:800, (Synaptic Systems, RRID:AB_2619998), antisubstance $P$ monoclonal rat, 1:500 (Millipore, RRID:AB_94639), for $48 \mathrm{~h}$ at $4{ }^{\circ} \mathrm{C}$ while shaking. Slices were rinsed 3 times in TBS for $10 \mathrm{~min}$ and transferred to either donkey antirabbit 555 (1:500), goat antiguinea pig 555 (1:500), goat antirat 488 (1:500), or goat antirat 555 
(1:500) secondary antibodies (Thermo Fisher), mixed with Nissl reagent in $0.3 \%$ Triton X-100/TBS, and incubated for $3 \mathrm{~h}$.

\section{Electrophysiology}

Preparation, incubation, and recording of IPN slices were carried out as described before [5]. Neurons in the LIPN were visually identified and the stimulating electrode was placed $\sim 100 \mu \mathrm{m}$ from the recording site. Patch pipettes $(2-4 M \Omega)$ were filled with an internal solution containing (in $\mathrm{mM}$ ): K-gluconate (130), $\mathrm{KCl}(10)$, $\mathrm{MgCl}_{2}$ (5), MgATP (5), GTP (0.2), HEPES (5), pH adjusted to 7.4 with $\mathrm{KOH}$. For plasticity experiments, synaptic currents were recorded at $-60 \mathrm{mV}$. Strychnine, substance P or CGP55845 was included in the ACSF containing bicuculline to elicit plasticity. For optogenetic experiments, blue light $(470 \mathrm{~nm}, 2 \mathrm{~ms})$ was emitted through the $\times 40$ water immersion objective from a Lumen 1600-LED (Prior). The rectification index experiments were carried out as described recently [5]. For studying electrically evoked GABAergic and glycinergic currents, an internal solution containing (in $\mathrm{mM}$ ): $\mathrm{CsCl}$ (130), HEPES (10), EGTA (0.5), MgATP (5), GTP (0.2), QX314 (5), pH adjusted to 7.4 with $\mathrm{CsOH}$, was used. sEPSCs were recorded at -60 $\mathrm{mV}$ in the presence bicuculline. sIPSCs were recorded at $-60 \mathrm{mV}$ in the presence DNQX and APV. Paired-pulse responses were evoked at an interstimulus interval of $50 \mathrm{~ms}$ [5]. NMDA EPSCs were evoked at $+40 \mathrm{mV}$ in the presence of bicuculline and CNQX $(100 \mu \mathrm{M})$.

\section{Stereotactic surgery and behavior}

Mice were anesthetized by a cocktail of ketamine $(75 \mathrm{mg} / \mathrm{kg})$ and xylazine $(5 \mathrm{mg} / \mathrm{kg})$ and placed on a stereotaxic apparatus (Stoelting Co.). A small hole was drilled using a microdrill. After 10 days of surgery, mice received the drug injection through an internal cannula (33G, Bregma: AP $-3.4 \mathrm{~mm}$; ML $1.3 \mathrm{~mm}$, DV $-4.9 \mathrm{~mm}$ ) using a manual injector. Fear conditioning and extinction were carried out as described recently [23]. Freezing was measured using FreezeFrame software (Coulbourn Instruments).

\section{Statistics}

Synaptic and membrane responses were analyzed using Clampfit 10.5 (Molecular Devices) and MiniAnalysis programs (Synaptosoft). Data are expressed as mean \pm SEM. Two-way ANOVA with Bonferroni post-hoc test and $t$-test were used for analyzing the data. $P<0.05$ was considered statistically significant.

\section{RESULTS}

Synaptic transmission in LIPN neurons

Consistent with the GABAergic nature of IPN neurons [6], LIPN neurons showed EGFP expression in GAD67-EGFP (G42) and tdTomato expression in PV-tdTomato mice, indicating that majority of LIPN neurons are parvalbumin-positive GABAergic neurons (Fig. 1b and Fig. S1) [24]. LIPN neurons exhibited spike frequency adaptation and spontaneous action potentials (Fig. 1c). The substance P-positive $\mathrm{dMHb}$ neurons are glutamatergic in nature and are expected to release glutamate onto the postsynaptic LIPN neurons [11]. To measure glutamatergic responses in LIPN neurons, we studied electrically evoked currents in the presence of $\mathrm{GABA}_{\mathrm{A}}$ receptor blocker bicuculline $(20 \mu \mathrm{M})$. We observed a robust electrically evoked synaptic response in LIPN neurons that was suppressed by a cocktail of an AMPA receptor antagonist, DNQX $(10 \mu \mathrm{M})$, and an NMDA receptor antagonist, APV $(50 \mu \mathrm{M})$ (Fig. 1d). However, we also observed a significant residual current after blocking glutamate and $\mathrm{GABA}_{\mathrm{A}}$ receptors. This residual current was partially blocked by strychnine $(1 \mu \mathrm{M})$, a glycine receptor antagonist, suggesting that synaptic stimulation in the LIPN leads to an activation of glycine receptors $\left(t_{9}=2.73\right.$, $P=0.02$ ). To determine whether $\mathrm{dMHb}$ neurons release glycine, we studied light-evoked currents in LIPN neurons from Tac1-ChR2EYFP mice that express channelrhodopsin in the substance
P-positive $\mathrm{dMHb}$ neurons. Consistent with the electrically evoked synaptic transmission, we were able to observe a robust lightevoked current in LIPN neurons in the presence of bicuculline, DNQX, and APV (Fig. 1e). This residual current was partially blocked by strychnine, confirming glycine receptor-mediated transmission in LIPN neurons $\left(t_{11}=3.18, P=0.009\right)$. However, we did not observe a residual current in the presence of CNQX $(100 \mu \mathrm{M})$, a kainate receptor blocker, and bicuculline, suggesting the absence of glycine corelease from the $\mathrm{dMHb}$ neurons (Fig. 1f). This result also suggested that kainate receptors play an important role in glutamate-evoked currents in LIPN neurons.

To confirm the lack of glycine corelease from $\mathrm{dMHb}$ neurons, we examined whether the axon terminals in the LIPN express the glycine transporters. Immunostaining for glycine transporters GlyT1 and GlyT2 from brain slices expressing YFP in substance P-positive neurons did not reveal the presence of GlyT1 and GlyT2 in YFP-expressing axons (Fig. 1g, h). However, we observed GlyT2positive axons within and on the borders of the LIPN (Fig. 1h). GlyT2 is expressed in glycinergic neurons [25]. Therefore, it is possible that glutamate activates these GlyT2-positive glycinergic axon terminals to enhance local glycine release.

Lack of activity-dependent plasticity in LIPN neurons

We have recently shown that the $\mathrm{VMHb}$-CIPN glutamatergic synapses undergo activity-dependent synaptic potentiation [5]. Therefore, we asked whether a similar plasticity occurs in LIPN neurons. First, we attempted an optogenetic stimulation protocol to induce plasticity in Tac1-ChR2-EYFP mice. We studied the amplitude of light-evoked currents in LIPN neurons in the presence of bicuculline. A comparison of synaptic current amplitude before and after a light stimulation at $10 \mathrm{~Hz}(5 \mathrm{~ms}$ pulses, for $15 \mathrm{~s}$ ) failed to reveal any change in synaptic strength in LIPN neurons (Fig. 2a) $\left(F_{1,29}=1.02, P=0.44\right)$. Next, we recorded electrically evoked synaptic currents in LIPN neurons in the presence of bicuculline before and after a $100 \mathrm{~Hz}$ stimulation (for $1 \mathrm{~s}$ ) applied through an extracellular electrode. In contrast to our previous study in the CIPN [5], we did not observe an increase in current amplitude in LIPN neurons following the $100 \mathrm{~Hz}$ stimulation (Fig. 2b) $\left(F_{1,29}=1.17, P=0.3\right)$. As an additional approach, we repeated the aforementioned experiment in which the postsynaptic neuron was depolarized to $0 \mathrm{mV}$ during the $100 \mathrm{~Hz}$ stimulation to allow for NMDA receptor activation. However, this modified protocol also did not result in synaptic potentiation (Fig. 2c) $\left(F_{1,29}=1.14, P=0.28\right)$. These results suggested that unlike the vMHb-CIPN pathway [5], the LIPN neurons do not exhibit an activity-dependent synaptic potentiation.

Blockade of glycine receptors reveals an activity-dependent plasticity in LIPN neurons

Given the glycine transmission in LIPN neurons (Fig. 1d, e), a concurrent activation of inhibitory glycine receptors might block the ability of glutamatergic synapses to undergo plasticity. Therefore, we asked whether blocking the glycine receptors enables activity-dependent plasticity in LIPN neurons. Consistent with this hypothesis, an application of $100 \mathrm{~Hz}$ electrical stimulation in the presence of strychnine and bicuculline resulted in a longlasting enhancement of peak current amplitude (Fig. $2 d)\left(F_{1,17}=\right.$ $50.7, P<0.001)$. Furthermore, this plasticity involved a reduction in the paired-pulse ratio, suggesting an enhancement of glutamate release (Fig. 2e) $\left(t_{5}=5.9, P=0.002\right)$. Since the $\mathrm{dMHb}$ neurons express high levels of substance $P$, which is known to enhance synaptic potentiation [11, 15] (Fig. 1b), we hypothesized that the activity-dependent synaptic potentiation in LIPN neurons depends upon endogenous substance P. Consistently, an NK1 receptor antagonist, L732138 (4 $\mu \mathrm{M}$, Tocris) $[26,27]$, blocked this activity-dependent synaptic potentiation in LIPN neurons (Fig. 2d) $\left(F_{1,16}=20.6, \quad P<0.001\right)$. Strychnine perfusion did not affect spontaneous glutamatergic transmission in LIPN neurons (Fig. S2). 
A

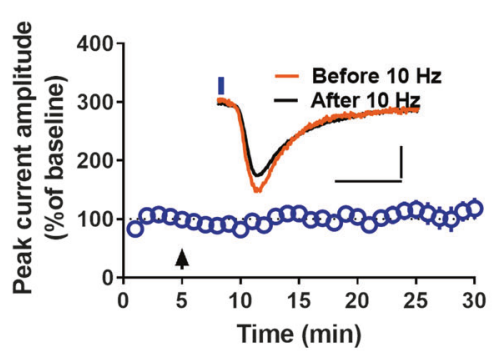

D

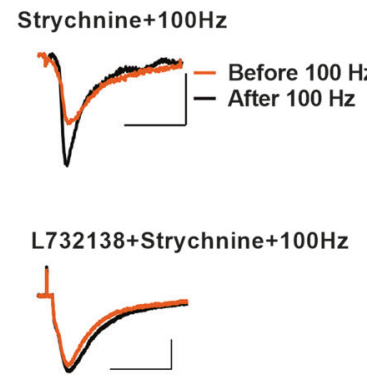

B
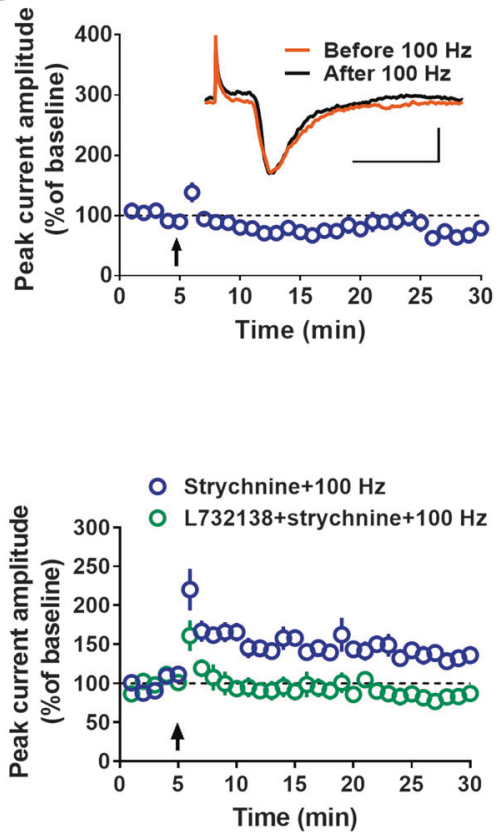

C

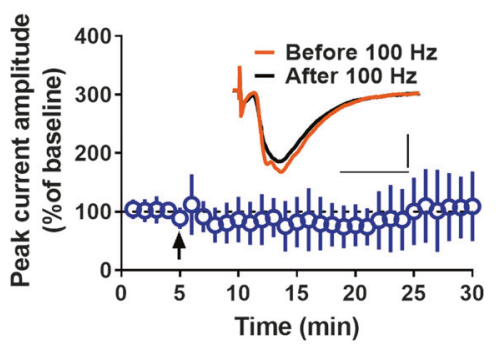

E

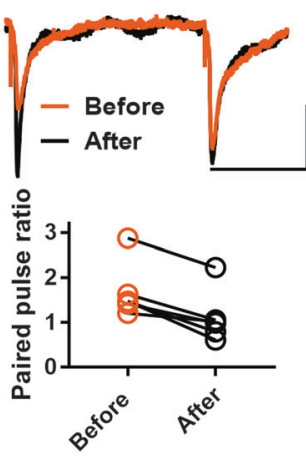

$\mathbf{F}$

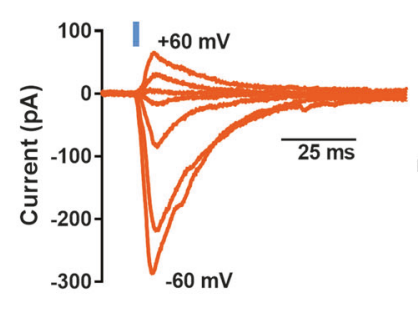

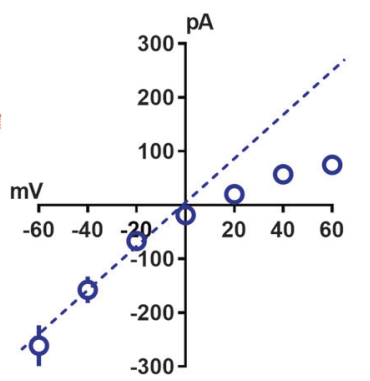

G APV+strychnine $+100 \mathrm{~Hz}$

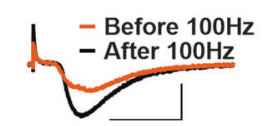

NASPM+strychnine $+100 \mathrm{~Hz}$

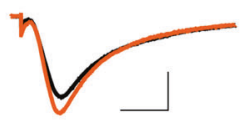

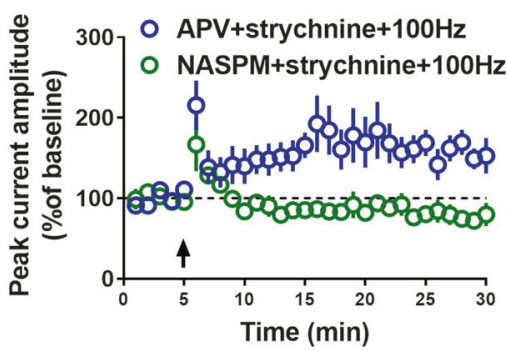

Fig. 2 Glycinergic transmission prevents activity-dependent plasticity in LIPN neurons. a A $10 \mathrm{~Hz}$ light stimulation for $15 \mathrm{~s}$ failed to affect the amplitude of light-evoked currents in Tac1-ChR2-EYFP mice ( $n=10$ neurons/5 mice). Inset shows example traces of light-evoked currents before and at $25 \mathrm{~min}$ after $10 \mathrm{~Hz}$ stimulation. Scale, $20 \mathrm{pA} / 15 \mathrm{~ms}$. b A $100 \mathrm{~Hz}$ electrical stimulation for $1 \mathrm{~s}$ did not affect the amplitude of electrically evoked currents in LIPN neurons ( $n=12$ neurons/10 mice). Inset shows example traces of evoked currents before and at 25 min after $100 \mathrm{~Hz}$ stimulation. Scale, $20 \mathrm{pA} / 15 \mathrm{~ms}$. c Depolarization of LIPN neurons to $0 \mathrm{mV}$ during the $100 \mathrm{~Hz}$ electrical stimulation did not affect the amplitude of electrically evoked currents in LIPN neurons $(n=11$ neurons/7 mice). Inset shows example traces of evoked currents before and at $25 \mathrm{~min}$ after $100 \mathrm{~Hz}$ stimulation. Scale, $100 \mathrm{pA} / 15 \mathrm{~ms}$. d An application of $100 \mathrm{~Hz}$ stimulation in the presence of strychnine produces a long-lasting enhancement of peak current amplitude in LIPN neurons ( $n=9$ neurons/ 6 mice). NKI receptor antagonist, L732138 blocks this plasticity ( $n=9$ neurons $/ 5$ mice). Left panel shows example traces before and at $25 \mathrm{~min}$ after $100 \mathrm{~Hz}$ stimulation. Scale, $50 \mathrm{pA} / 10 \mathrm{~ms}$ (upper), $20 \mathrm{pA} / 10 \mathrm{~ms}$ (lower). e Synaptic plasticity in the presence of strychnine involves a reduction in paired-pulse ratio ( $n=6$ neurons/4 mice). Upper panel shows example traces before and at $25 \mathrm{~min}$ after $100 \mathrm{~Hz}$ stimulation. Scale, $50 \mathrm{pA} / 25 \mathrm{~ms}$. f LIPN neurons express synaptic CPARs as indicated by the significant inward rectification of glutamatergic currents. Left panel shows example traces of currents recorded at -60 , $-40,-20,0,+20,+40$ and $+60 \mathrm{mV}$. Right panel shows current/voltage relationship (I-V) plot of synaptic currents indicating inward rectification ( $n=11$ neurons/6 mice). g NASPM ( $n=9$ neurons $/ 5$ mice) but not APV ( $n=12$ neurons/8 mice), blocked activity-dependent plasticity in the presence of strychnine. Left panel shows example traces. Scale, 50 pA/10 ms (upper), 100 pA/5 ms (lower). Arrows indicate the application of 10 or $100 \mathrm{~Hz}$ stimulation. Blue line indicates light activation

Congruent with the high expression of $\mathrm{Ca}^{2+}$-permeable AMPA receptors (CPARs) in GABAergic neurons [28, 29], both CIPN and LIPN neurons express high levels of synaptic CPARs, as shown by a robust inward rectification of AMPA currents [5] (Fig. 2f). Similar to the previously described NMDA receptor-independent plasticity in GABAergic neurons [28, 29], CPARs are necessary for activitydependent plasticity in CIPN neurons [5]. Therefore, we tested whether CPARs play a similar role in LIPN neurons. A perfusion of I-Naphthyl acetyl spermine trihydrochloride (NASPM, $100 \mu \mathrm{M}$ ), a CPAR antagonist, blocked the aforementioned long-lasting synaptic potentiation $\left(F_{1,16}=26.9, P<0.001\right)$, suggesting that CPARs are required for this plasticity (Fig. 2g). However, APV, an NMDA receptor antagonist, failed to block this plasticity $\left(F_{1,19}=0.36, P<0.55\right)$, suggesting that the activity-dependent plasticity in LIPN neurons is NMDA receptor-independent (Fig. $2 \mathrm{~g}$ ).

Exogenous substance $\mathrm{P}$ enhances activity-dependent plasticity in LIPN neurons

The $\mathrm{dMHb}$ inputs to the LIPN show a robust expression of substance $P$ (Fig. 1b). Consistently, NK1 receptors are necessary for activity-dependent synaptic potentiation in LIPN neurons (Fig. 2d). Therefore, we asked whether exogenous substance P could overcome the lack of activity-dependent plasticity in LIPN neurons in the presence of glycinergic transmission. 
A

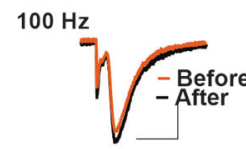

Substance $\mathrm{P}+100 \mathrm{~Hz}$

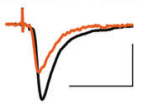

C

U73122+substance $P$ $+100 \mathrm{~Hz}$

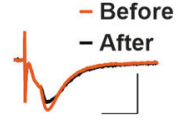

U73343+substance $P$ $+100 \mathrm{~Hz}$

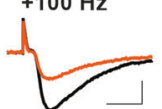

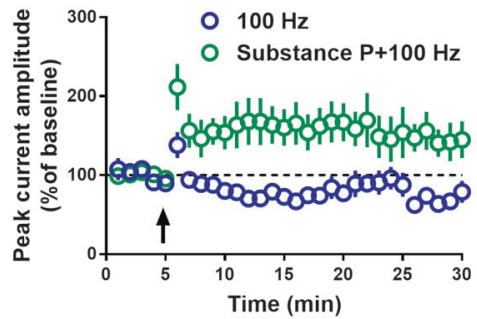

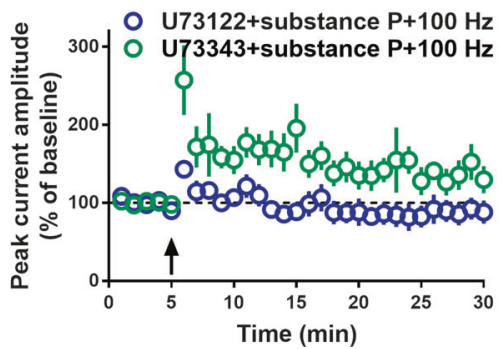

B
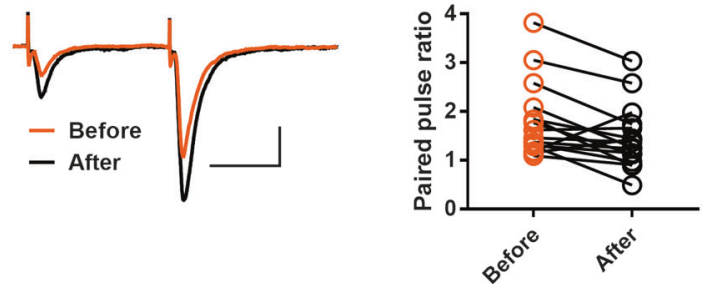

D
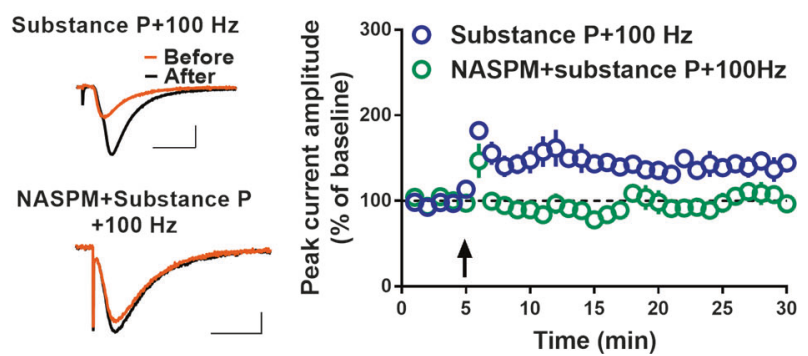

Fig. 3 High-frequency activity in the presence of exogenous substance $\mathrm{P}$ induces synaptic potentiation in LIPN neurons. a $\mathrm{A} 100 \mathrm{~Hz}$ stimulation in the presence of substance $P$ induces a long-lasting potentiation of synaptic transmission in the LIPN neurons ( $n=12$ neurons/ 7 mice). Data for $100 \mathrm{~Hz}$ stimulation in the absence of substance $\mathrm{P}$ are same as Fig. $2 \mathrm{~b}$. Left panels show example traces. Scale, $20 \mathrm{pA} / 25 \mathrm{~ms}$ (top), $50 \mathrm{pA} / 25 \mathrm{~ms}$ (bottom). b Paired-pulse ratio before and after $100 \mathrm{~Hz}$ stimulation in the presence of substance $\mathrm{P}$ ( $n=16 \mathrm{neurons} / 15 \mathrm{mice}$ ). Left panel shows example traces. Scale, 200 pA/25 ms. c PLC inhibitor, U73122 ( $n=11$ neurons/7 mice) but not its inactive analog, U73433 ( $n=12$ neurons/6 mice), blocked activity-induced plasticity in the presence of substance P. Left panels show example traces. Scale, 20 pA/ $10 \mathrm{~ms}$ (top and bottom). d NASPM ( $n=10$ neurons/7 mice) blocked activity-induced plasticity in the presence of substance P. An application of $100 \mathrm{~Hz}$ stimulation in the presence of substance $\mathrm{P}$ produced a robust synaptic potentiation ( $n=10$ neurons/10 mice). Left panels show example traces. Scale, $100 \mathrm{pA} / 10 \mathrm{~ms}$ (top), $10 \mathrm{pA} / 10 \mathrm{~ms}$ (bottom). Arrows indicate the application of $100 \mathrm{~Hz}$ stimulation

An application of $100 \mathrm{~Hz}$ stimulation for $1 \mathrm{~s}$ in the presence of substance $P(1 \mu \mathrm{M})$ and bicuculline produced a long-lasting enhancement of current amplitude (Fig. 3a) $\left(F_{1,20}=10.6, P=\right.$ 0.004). Similar to the synaptic potentiation in the presence of strychnine (Fig. 2d, e), this plasticity involved a reduction in the paired-pulse ratio, suggesting an enhanced glutamate release (Fig. $3 \mathrm{~b})\left(t_{15}=2.88, P=0.01\right)$. Consistent with the putative NK1 receptor-mediated PLC signaling [16], a PLC inhibitor, U73122 $(1 \mu \mathrm{M})$, blocked this plasticity, suggesting the role of PLC in substance P-dependent synaptic potentiation in LIPN neurons (Fig. 3c). However, U73433 (1 $\mu \mathrm{M})$, an inactive analog of U73122, failed to block substance P-dependent synaptic potentiation in LIPN neurons (Fig. 3c) $\left(F_{1,21}=11.2, P=0.003\right.$, comparison of U73122 and U73433 groups). Similar to the activitydependent plasticity in the presence of strychnine (Fig. 2g), NASPM blocked substance P-dependent long-lasting potentiation in LIPN neurons, confirming the role of CPARs in activitydependent plasticity in LIPN neurons (Fig. 3d) $\left(F_{1,18}=17.7, P=\right.$ 0.001). Apart from the effect of substance $P$ on synaptic potentiation in the LIPN, a perfusion of substance $\mathrm{P}$ produced a selective enhancement of glutamate release in LIPN neurons in an NK1 receptor-dependent manner (Fig. S3a). However, substance $P$ did not affect GABAergic transmission (Fig. S3b), AMPA, and NMDA receptor transmission (Fig. S3c, d), the presence of synaptic CPARs (Fig. S3e), glycinergic transmission (Fig. S4) or the excitability in LIPN neurons (Fig. S5a, b).

Synaptic potentiation in the LIPN involves $\mathrm{CB} 1$ receptor activation Since the LIPN expresses high levels of CB1 receptors [3] (Fig. 4a), we asked whether $\mathrm{CB} 1$ receptors play a role in synaptic plasticity in LIPN neurons. An application of $100 \mathrm{~Hz}$ stimulation in the presence of strychnine, bicuculline, and AM251 (5 $\mu \mathrm{M})$, a CB1 receptor antagonist, did not show an increase in peak current amplitude $\left(F_{1,29}=0.63, P=0.65\right)$ (Fig. $\left.4 \mathrm{~b}\right)$, suggesting that $C B 1$ receptors are necessary for activity-dependent synaptic potentiation in LIPN neurons. Similarly, an application of $100 \mathrm{~Hz}$ stimulation in the presence of substance $P$, bicuculline, and AM251 failed to show an increase in current amplitude $\left(F_{1,29}=1.7, P=0.15\right)$ (Fig. 4c). These results suggested that activity-dependent synaptic potentiation in the LIPN involves the release of endocannabinoids and activation of $\mathrm{CB} 1$ receptors. Given the putative role of presynaptic $C B 1$ receptors in the negative regulation of neurotransmitter release [30], we examined the effect of CB1 receptor activation on glutamate and GABA release onto LIPN neurons. $A$ perfusion of WIN552122 $(2 \mu \mathrm{M})$, a CB1 receptor agonist, failed to modify glutamatergic transmission in LIPN neurons $\left(F_{1,24}=0.45\right.$, $P=0.7$ ) (Fig. 4d). However, WIN552122 perfusion resulted in a significant suppression of GABAergic transmission $\left(F_{1,24}=7.1, P<\right.$ 0.001 ) (Fig. 4e). Since an activity-dependent release of endocannabinoids is known to act on presynaptic CB1 receptors to suppress neurotransmitter release [31], we hypothesized that the endocannabinoid release during high-frequency activity leads to a suppression of GABA release from LIPN neurons and hence a diminished activation of $G_{A B A_{B}}$ receptors. Unlike in the $\mathrm{vMHb}$ CIPN synapses, where $G_{A B A_{B}}$ receptors are excitatory $[4,5]$, baclofen $(1 \mu \mathrm{M})$, a $G_{A B A_{B}}$ receptor agonist, suppressed synaptic transmission in LIPN neurons (Fig. S6) $\left(F_{1,24}=2.99, P=0.03\right)$. Therefore, a suppression of $G_{A B A_{B}}$ receptor activity might permit activity-dependent synaptic potentiation in LIPN neurons. To test this hypothesis, we asked whether a mere suppression of $G A B A_{B}$ receptor activity allows for activity-dependent plasticity in LIPN neurons. An application of $100 \mathrm{~Hz}$ stimulation in the presence of CGP55845 $(5 \mu \mathrm{M})$, a $\mathrm{GABA}_{B}$ receptor antagonist, and bicuculline resulted in a robust long-lasting potentiation of peak current amplitude in LIPN neurons (Fig. 5a) $\left(F_{1,29}=4.3, P<0.001\right)$. Similar to the activity-dependent plasticity in the presence of strychnine (Fig. 2d, e) or exogenous substance P (Fig. 3a, b), the activitydependent plasticity in the presence of CGP55845 also resulted in 
A
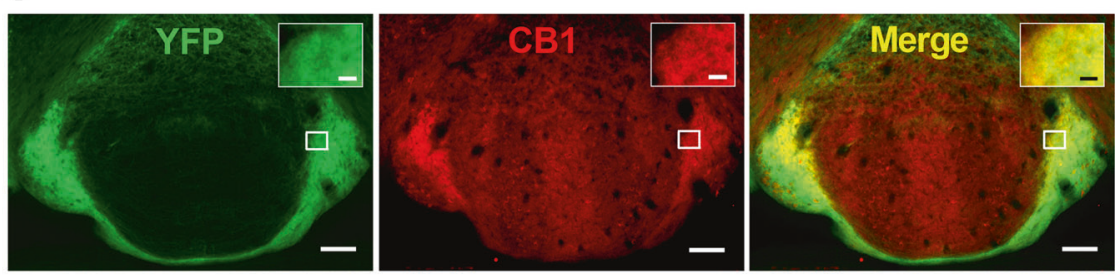

B

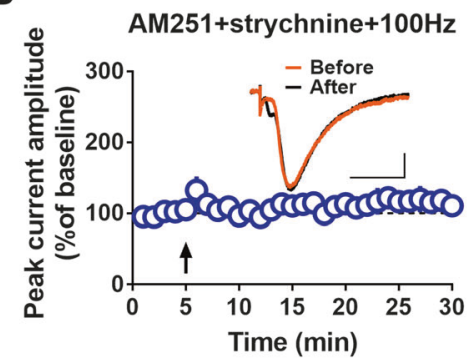

D

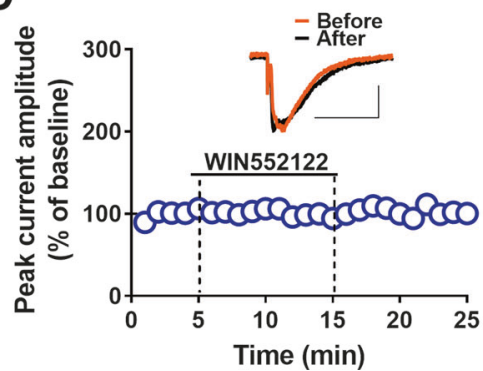

C

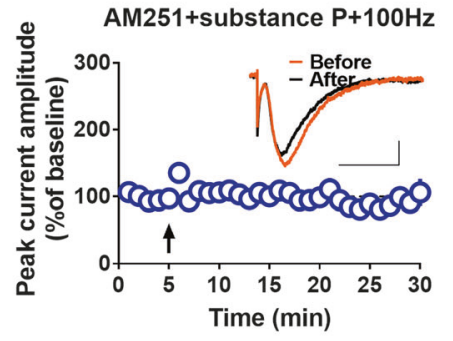

E

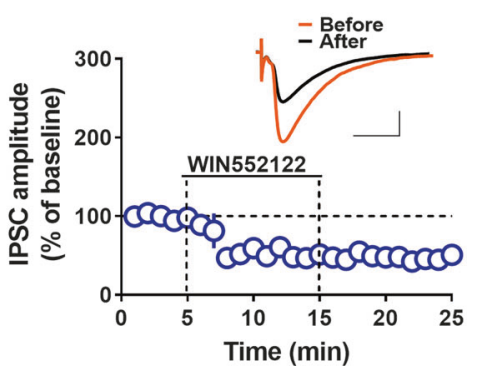

Fig. 4 Synaptic plasticity in LIPN neurons involves an activation of CB1 receptors. a CB1 receptor staining in the IPN of mice expressing YFP in dMHb neurons. Scale 100/12.5 (inset) $\mu \mathrm{m}$. b AM251, a CB1 receptor antagonist blocks activity-dependent plasticity in the presence of strychnine ( $n=10$ neurons/7 mice). Left panel shows example traces. Scale, $20 \mathrm{pA} / 10 \mathrm{~ms}$. c AM251 blocks activity-dependent plasticity in the presence of exogenous substance $\mathrm{P}(n=9$ neurons/5 mice). Left panel shows example traces. Scale, $20 \mathrm{pA} / 10 \mathrm{~ms}$. d WIN552122, a CB1 agonist, failed to modify glutamatergic transmission in LIPN neurons ( $n=8$ neurons $/ 5$ mice). Left panel shows example traces. Scale, $25 \mathrm{pA} / 25 \mathrm{~ms}$. e WIN552122 suppresses GABAergic transmission in LIPN neurons ( $n=9$ neurons/5 mice). Left panel shows example traces. Scale, $200 \mathrm{pA} / 10 \mathrm{~ms}$

a decrease in the paired-pulse ratio, suggesting a shared presynaptic expression of plasticity (Fig. 5a) $\left(t_{8}=2.6, P=0.03\right)$. However, AM251 failed to block activity-dependent synaptic potentiation in the presence of CGP55845 (Fig. 5b), suggesting that circumventing the role of a $\mathrm{CB} 1$ receptor-mediated suppression of GABA release by a direct blockade of $G A B A_{B}$ receptors was sufficient to elicit this plasticity. These results suggested that an activity-induced release of endocannabinoids suppresses GABA release, resulting in a diminished $G_{A B A}$ receptor activation and a disinhibition of $\mathrm{dMHb}$ terminals, which allows substance $P$ to induce a long-lasting increase in glutamate release in the LIPN. To test this hypothesis, we studied the effect of substance $P$ on glutamatergic transmission in LIPN neurons in the presence of CGP55845 and bicuculline. A 10 min perfusion of substance $P$ and CGP55845 in the presence of bicuculline produced a significant increase in glutamatergic transmission compared to a similar perfusion of substance $P$ in the absence of CGP55845 $\left(F_{1,17}=18.4, \quad P<0.001\right) \quad$ (Fig. 5C). Furthermore, this substance $\mathrm{P}$-induced potentiation of glutamatergic transmission involved a significant decrease in paired-pulse ratio suggesting an enhanced glutamate release $\left(t_{8}=2.9, P=0.01\right)$ (Fig. $5 \mathrm{c}$ ). A perfusion of CGP55845 in the presence of bicuculline did not affect glutamatergic transmission $\left(F_{1,24}=1.04, P=0.39\right)$ (Fig. 5c). Therefore, an activity-induced suppression of $G_{A B A}$ receptor activity might enable the coreleasing substance $P$ to produce a long-lasting increase in glutamate release from $\mathrm{dMHb}$ terminals.

Substance $P$ signaling in the IPN is involved in fear extinction Since the substance P-mediated signaling is necessary for synaptic potentiation in LIPN neurons, we asked whether NK1 receptors in the IPN play a role in fear extinction. Mice were fear conditioned on day 1 . On day 2 , the conditioned mice received a stereotactic injection of an NK1 receptor antagonist, L732138 $(1 \mu \mathrm{l}, 0.5 \mu \mathrm{M}$, 10-15 min), or vehicle into the IPN 30 min before they underwent fear extinction training. Although L732138 did not affect extinction learning, there was significant impairment of extinction memory (Fig. S7b). However, a local injection of L732138 before fear conditioning did not affect fear memory (Fig. S7c). These results suggested a selective role of substance $P$ in the IPN in fear extinction.

\section{DISCUSSION}

Our current study demonstrates a previously unknown glutamatergic plasticity in LIPN neurons regulated through opposing actions of glycinergic and substance $P$ transmission. While substance $P$ enhances activity-dependent synaptic potentiation in LIPN neurons, glycine receptor activity prevents this plasticity. The IPN is one of the brain areas with the highest expression of 

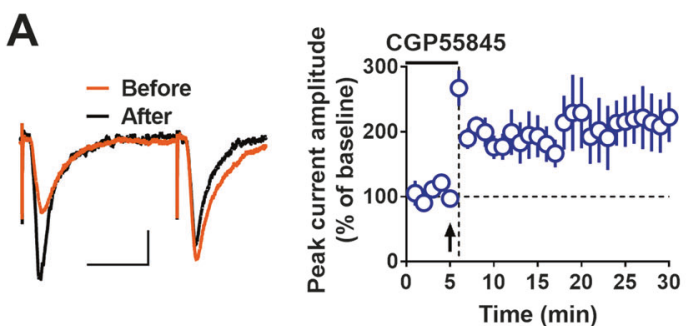

C
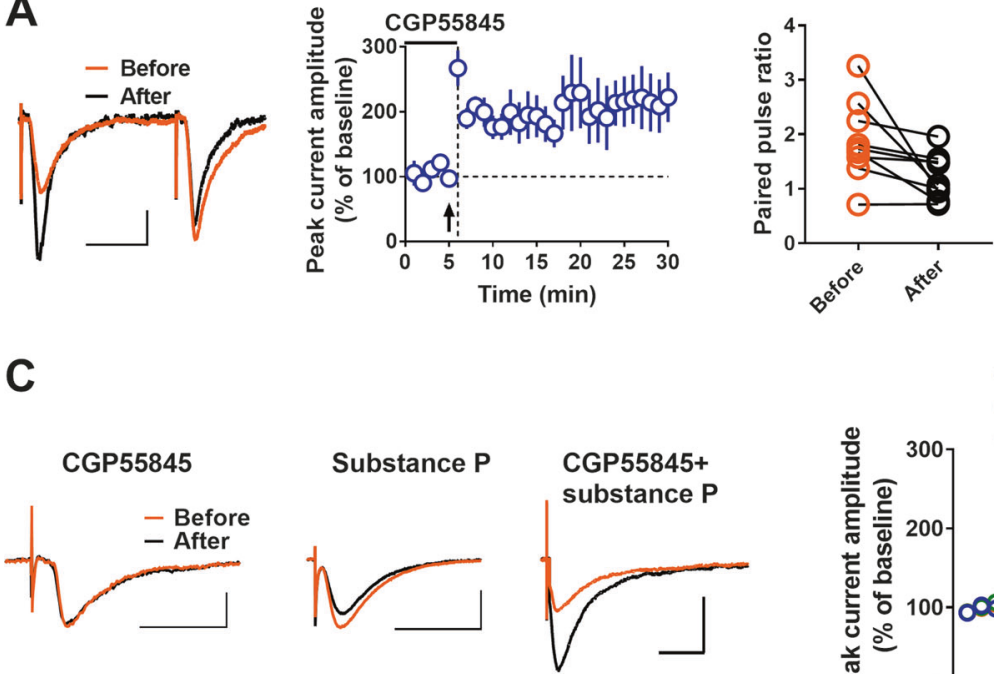

B
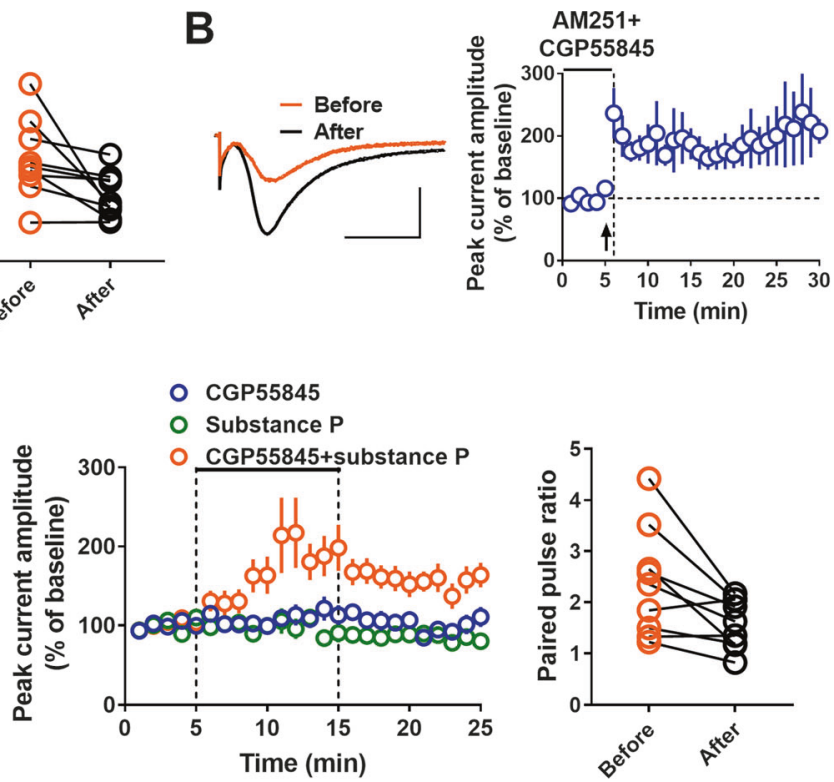

D

1. Basal state

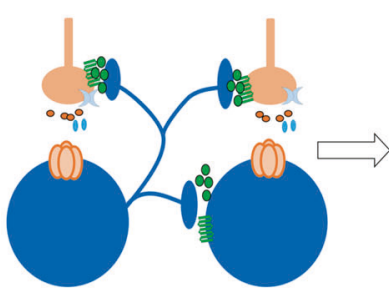

Glutamate
2. Activity leads to glutamate release and CPAR activation
3. Endocannabinoid $(E C)$ releasesuppression of GABA releasediminished $\mathrm{GABA}_{\mathrm{B}} \mathrm{R}$ activation
4. The suppressed $G A B A_{B} R$ activity and activation of pre-synaptic NK1R lead to a long-lasting enhancement of glutamate release
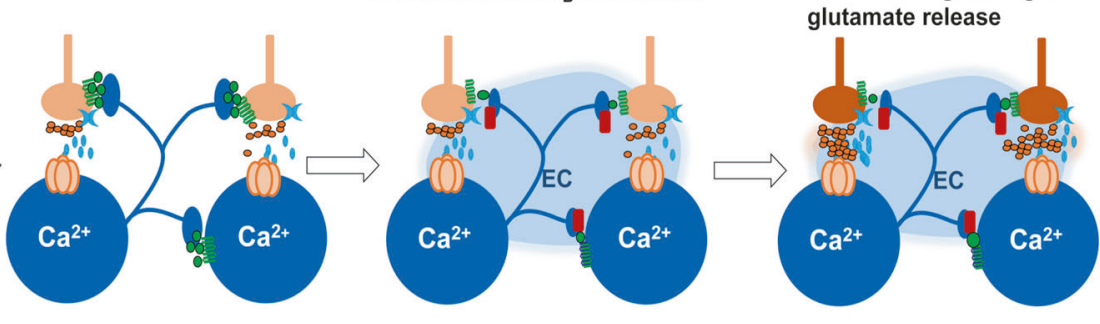

Substance P (O) CPAR

NK1R

GABA

$\mathrm{GABA}_{\mathrm{B}} \mathrm{R} \quad \mathrm{ICB} 1 \mathrm{R}$

Fig. 5 A suppression of $\mathrm{GABA}_{B}$ receptor activity allows for activity-dependent synaptic potentiation in LIPN neurons (a) CGP55845, a $\mathrm{GABA}_{\mathrm{B}}$ antagonist, enhances activity-dependent plasticity in LIPN neurons ( $n=9$ neurons $/ 5$ mice). Left panel shows example traces. Scale, $20 \mathrm{pA} / 20 \mathrm{~ms}$. Right panel shows paired-pulse ratio before and after $100 \mathrm{~Hz}$ stimulation in the presence of CGP55845 ( $n=9 \mathrm{neurons} / 5 \mathrm{mice}$ ). b AM251 does not block synaptic potentiation induced by $100 \mathrm{~Hz}$ stimulation in the presence of CGP55845 ( $n=9$ neurons/5 mice). Left panel shows example traces. Scale, $20 \mathrm{pA} / 10 \mathrm{~ms}$. c Substance P produces a long-lasting potentiation of glutamate release in LIPN neurons in the presence of CGP55845 and bicuculline $(n=11$ neurons/7 mice). Neither substance P $(n=8$ neurons/4 mice) nor CGP55845 $(n=7$ neurons/3 mice) affects evoked glutamatergic transmission in LIPN neurons in the presence of bicuculline. Left panel shows example traces. Scale, $20 \mathrm{pA} / 10 \mathrm{~ms}$ (left), $50 \mathrm{pA} / 25 \mathrm{~ms}$ (middle), $50 \mathrm{pA} / 10 \mathrm{~ms}$ (right). Middle panel shows the average peak current amplitude in LIPN neurons. Right panel shows paired-pulse ratio in LIPN neurons before and after the perfusion of substance P and CGP5584. d Mechanism of activitydependent plasticity in LIPN neurons. Activity causes the release of glutamate, which leads to an activation of postsynaptic CPARs. The resulting increase in calcium causes the release of endocannabinoids, which activate the CB1 receptors on the GABAergic LIPN neurons to decrease GABA release. The suppression of $G_{A B A}$ receptor-mediated inhibition within the LIPN coinciding with an effect of synaptically released substance $P$ on the $\mathrm{dMHb}$ terminals result in a long-lasting enhancement of glutamate release

glycine receptors [17]. However, a lack of glycine transporter expression in $\mathrm{dMHb}$ axons within the LIPN, as well as a lack of monosynaptic glycinergic currents in LIPN neurons in the presence of an AMPA/kainate receptor blocker, suggested an absence of glycine corelease from $\mathrm{dMHb}$ neurons. On the other hand, we observed axonal fibers in the LIPN that express GlyT2, a glycine transporter present in glycinergic neurons [25]. Therefore, the dMHb-derived glutamate might activate GlyT2-positive axons, resulting in local glycine release in the LIPN. This glycinergic transmission might provide a tight control of excitatory/inhibitory balance in LIPN neurons. A blockade of glycine receptors was able to reveal an activity-dependent synaptic potentiation in LIPN neurons, which was otherwise unobservable. More importantly, this plasticity was NK1 receptor dependent, suggesting the role of endogenous substance $P$ in activity-dependent synaptic potentiation in the LIPN. In addition, an exogenous application of substance $\mathrm{P}$ was able to overcome a glycine receptor-mediated inhibition of plasticity in LIPN neurons. Therefore, substance $P$ and glycine receptors regulate LIPN plasticity in an opposite manner. Consistent with the notion that the strength of the excitatory drive onto IPN neurons is inversely correlated with the expression of fear behavior [3-5], substance P-mediated signaling is necessary for both synaptic potentiation in LIPN neurons and fear extinction. Therefore, substance $P$ release from the $\mathrm{dMHb}$ neurons during safety signal learning could induce LIPN potentiation to mediate fear extinction. Our current findings are particularly noteworthy given that the IPN is upstream of the median raphe nucleus, the midbrain nucleus that directly modulates the hippocampus and the $\mathrm{mPFC}$ and is involved in the negative regulation of fear memory [32-36].

It is worth noting that the plasticity observed in the GABAergic LIPN neurons is similar to the previously described CPAR-dependent 
Opposing effects of an atypical glycinergic and substance $\mathrm{P}$ transmission...

plasticity in GABAergic neurons [5, 28, 29]. The activation of both CPARs and substance P-mediated signaling is necessary for synaptic potentiation in LIPN neurons. The activation of CPARs in LIPN neurons might result in the release of endocannabinoids, which in turn suppress GABA release via CB1 receptors. Consistently, a pharmacological activation of $\mathrm{CB} 1$ receptors suppresses GABAergic but not glutamatergic transmission in LIPN neurons. It is plausible that GABA exerts a tonic inhibition of activity-dependent plasticity through $G_{A B A}$ receptors, which is suppressed by the activityinduced release of endocannabinoids. Congruent with this notion, high-frequency activity in the presence of a $G A B A_{B}$ receptor antagonist produced a robust and long-lasting presynaptic potentiation. The $\mathrm{MHb}$ neurons and their axonal output to the IPN, the fasciculus retroflexus, express the highest level of $G A B A_{B}$ receptors in the brain $[20,21]$. In contrast to the inhibitory role of $G A B A_{B}$ receptors on plasticity in LIPN neurons, the unique excitatory $G_{A B A}$ receptors are required for activity-dependent synaptic potentiation in the vMHb-CIPN pathway $[4,5]$. Therefore, $\mathrm{GABA}_{\mathrm{B}}$ receptors play opposite roles in activity-dependent plasticity at $\mathrm{dMHb}$-LIPN and $\mathrm{vMHb}-\mathrm{CIPN}$ synapses. Exogenous substance $\mathrm{P}$ produces a selective increase in spontaneous glutamate release without affecting evoked glutamatergic transmission, which might be due to an NK1 receptormediated increase in the excitability of $\mathrm{MHb}$ terminals [37]. However, exogenous substance $P$ produces a long-lasting increase in evoked glutamate release in the presence of $\mathrm{GABA}_{\mathrm{B}}$ receptor blocker. This plasticity mimics the activity-dependent presynaptic plasticity in LIPN neurons in the presence of exogenous substance $P$, strychnine or CGP55845. While the activity-dependent plasticity in the presence of strychnine and exogenous substance $P$ requires the release of endocannabinoids, the activity-dependent plasticity in the presence of CGP55845 does not require the release of endocannabinoids, as a direct inhibition of $G A B A_{B}$ receptors circumvents the need for a suppression of GABA release. Irrespective of the mode of induction of plasticity, a long-lasting increase in glutamatergic transmission in LIPN neurons requires a suppression of $G_{A B A}$ receptor activity and a concomitant substance P-mediated signaling. In activitydependent plasticity in LIPN neurons, a suppression of $G_{A B A}$ activity allows the $\mathrm{dMHb}$-derived substance $\mathrm{P}$ to produce a longlasting increase in glutamate release (Fig. 5d). Consistently, the activity-dependent synaptic potentiation in LIPN neurons is NK1 receptor- and PLC-dependent. Earlier studies have shown that substance P-dependent synaptic potentiation involves NK1 receptor-PLC signaling [38].

In conclusion, our study demonstrates a unique plasticity in the LIPN, which is regulated by four key synaptic partners: substance $P$, $\mathrm{CB} 1, \mathrm{GABA}_{\mathrm{B}}$, and glycine receptors, all of which are abundantly expressed in the MHb-IPN pathway [3, 17-21]. Furthermore, we demonstrate a region-specific role of substance $P$ in fear extinction.

\section{FUNDING AND DISCLOSURE}

This work was supported by NIH (HD076914 to IN). The authors declare no competing interests.

\section{ACKNOWLEDGEMENTS}

The authors thank Dr. Francis S. Lee (Department of Psychiatry, Weill Cornell Medical College), and the labs of Drs. Nicolas Tritsch, Bernardo Rudy, Jayeeta Basu, and Arjun Masurkar (NYU Langone Medical Center) for help with the experiments.

\section{ADDITIONAL INFORMATION}

Supplementary Information accompanies this paper at (https://doi.org/10.1038/ s41386-019-0396-6).

Publisher's note: Springer Nature remains neutral with regard to jurisdictional claims in published maps and institutional affiliations.

\section{REFERENCES}

1. Sutherland RJ. The dorsal diencephalic conduction system: a review of the anatomy and functions of the habenular complex. Neurosci Biobehav Rev. 1982;6:1-13.

2. Antolin-Fontes B, Ables JL, Gorlich A, Ibanez-Tallon I. The habenulointerpeduncular pathway in nicotine aversion and withdrawal. Neuropharmacology. 2015;96(Pt B):213-22.

3. Soria-Gomez E, Busquets-Garcia A, Hu F, Mehidi A, Cannich A, Roux L, et al. Habenular $C B 1$ receptors control the expression of aversive memories. Neuron. 2015;88:306-13.

4. Zhang J, Tan L, Ren Y, Liang J, Lin R, Feng Q, et al. Presynaptic excitation via $\mathrm{GABAB}$ receptors in habenula cholinergic neurons regulates fear memory expression. Cell. 2016;166:716-28.

5. Koppensteiner $P$, Melani R, Ninan I. A cooperative mechanism involving Ca2+-permeable AMPA receptors and retrograde activation of GABAB receptors in interpeduncular nucleus plasticity. Cell Rep. 2017;20:1111-22.

6. Quina LA, Harris J, Zeng $H$, Turner EE. Specific connections of the interpeduncular subnuclei reveal distinct components of the habenulopeduncular pathway. J Comp Neurol. 2017;525:2632-56.

7. Andres $\mathrm{KH}$, von During $\mathrm{M}$, Veh RW. Subnuclear organization of the rat habenular complexes. J Comp Neurol. 1999;407:130-50.

8. Contestabile A, Villani L, Fasolo A, Franzoni MF, Gribaudo L, Oktedalen O. et al. Topography of cholinergic and substance $P$ pathways in the habenulointerpeduncular system of the rat. an immunocytochemical and microchemical approach. Neuroscience. 1987;21:253-70.

9. Kobayashi Y, Sano Y, Vannoni E, Goto H, Suzuki H, Oba A, et al. Genetic dissection of medial habenula-interpeduncular nucleus pathway function in mice. Front Behav Neurosci. 2013;7:17.

10. Yamaguchi T, Danjo T, Pastan I, Hikida T, Nakanishi S. Distinct roles of segregated transmission of the septo-habenular pathway in anxiety and fear. Neuron. 2013;78:537-44.

11. Qin C, Luo M. Neurochemical phenotypes of the afferent and efferent projections of the mouse medial habenula. Neuroscience. 2009;161: 827-37.

12. Ren J, Qin C, Hu F, Tan J, Qiu L, Zhao S, et al. Habenula "cholinergic" neurons co-release glutamate and acetylcholine and activate postsynaptic neurons via distinct transmission modes. Neuron. 2011;69:445-52.

13. Granger AJ, Wallace ML, Sabatini BL. Multi-transmitter neurons in the mammalian central nervous system. Curr Opin Neurobiol. 2017;45: 85-91.

14. Steinhoff MS, von Mentzer B, Geppetti P, Pothoulakis C, Bunnett NW. Tachykinins and their receptors: contributions to physiological control and the mechanisms of disease. Physiol Rev. 2014;94:265-301.

15. Masterson SP, Li J, Bickford ME. Frequency-dependent release of substance $P$ mediates heterosynaptic potentiation of glutamatergic synaptic responses in the rat visual thalamus. J Neurophysiol. 2010;104:1758-67.

16. Fukuhara S, Shimizu M, Matsushima H, Mukai H, Munekata E. Signaling pathways via NK1 receptors and their desensitization in an AR42J cell line. Peptides. 1998;19:1349-57.

17. Frostholm A, Rotter A. Glycine receptor distribution in mouse CNS: autoradiographic localization of [3H]strychnine binding sites. Brain Res Bull. 1985;15: 473-86.

18. Hokfelt T, Kellerth JO, Nilsson G, Pernow B. Substance p: localization in the central nervous system and in some primary sensory neurons. Science. 1975;190:889-90.

19. Cuello AC, Emson PC, Paxinos G, Jessell T. Substance P containing and cholinergic projections from the habenula. Brain Res. 1978;149:413-29.

20. Bischoff S, Leonhard S, Reymann N, Schuler V, Shigemoto R, Kaupmann K, et al. Spatial distribution of GABA(B)R1 receptor mRNA and binding sites in the rat brain. J Comp Neurol. 1999;412:1-16.

21. Fritschy JM, Meskenaite $V$, Weinmann $O$, Honer $M$, Benke $D$, Mohler $H$ GABAB-receptor splice variants $\mathrm{GB1a}$ and $\mathrm{GB} 1 \mathrm{~b}$ in rat brain: developmental regulation, cellular distribution and extrasynaptic localization. Eur J Neurosci. 1999;11:761-8.

22. Dincheva I, Yang J, Li A, Marinic T, Freilingsdorf $H$, Huang $C$, et al. Effect of earlylife fluoxetine on anxiety-like behaviors in BDNF Val66Met mice. Am J Psychiatry. 2017;174:1203-13.

23. Koppensteiner P, Galvin C, Ninan I. Lack of experience-dependent intrinsic plasticity in the adolescent infralimbic medial prefrontal cortex. Synapse. 2019;73: e22090.

24. Chattopadhyaya B, Di Cristo G, Higashiyama H, Knott GW, Kuhlman SJ, Welker E, et al. Experience and activity-dependent maturation of perisomatic GABAergic innervation in primary visual cortex during a postnatal critical period. J Neurosci. 2004;24:9598-611. 
25. Zafra F, Aragon C, Olivares L, Danbolt NC, Gimenez C, Storm-Mathisen J. Glycine transporters are differentially expressed among CNS cells. J Neurosci. 1995; 15(5 Pt 2):3952-69.

26. MacLeod AM, Merchant KJ, Cascieri MA, Sadowski S, Ber E, Swain CJ, et al. $\mathrm{N}$-acyl-L-tryptophan benzyl esters: potent substance $\mathrm{P}$ receptor antagonists. J Med Chem. 1993;36:2044-5.

27. Cascieri MA, Macleod AM, Underwood D, Shiao LL, Ber E, Sadowski S, et al. Characterization of the interaction of N-acyl-L-tryptophan benzyl ester neurokinin antagonists with the human neurokinin-1 receptor. J Biol Chem. 1994;269: 6587-91.

28. Mahanty NK, Sah P. Calcium-permeable AMPA receptors mediate long-term potentiation in interneurons in the amygdala. Nature. 1998;394:683-7.

29. Lamsa KP, Heeroma JH, Somogyi P, Rusakov DA, Kullmann DM. Anti-hebbian long-term potentiation in the hippocampal feedback inhibitory circuit. Science. 2007;315:1262-6.

30. Ohno-Shosaku T, Kano M. Endocannabinoid-mediated retrograde modulation of synaptic transmission. Curr Opin Neurobiol. 2014;29:1-8.

31. Lee SH, Foldy C, Soltesz I. Distinct endocannabinoid control of GABA release at perisomatic and dendritic synapses in the hippocampus. J Neurosci. 2010;30: 7993-8000.
32. Azmitia EC, Segal M. An autoradiographic analysis of the differential ascending projections of the dorsal and median raphe nuclei in the rat. J Comp Neurol. 1978;179:641-67.

33. Deakin J. The origins of ' $5-\mathrm{HT}$ and mechanisms of defence' by Deakin and Graeff: a personal perspective. J Psychopharmacol. 2013;27:1084-9.

34. Varga V, Losonczy A, Zemelman BV, Borhegyi Z, Nyiri G, Domonkos A, et al. Fast synaptic subcortical control of hippocampal circuits. Science. 2009;326: 449-53.

35. Wang DV, Yau HJ, Broker CJ, Tsou JH, Bonci A, Ikemoto S. Mesopontine median raphe regulates hippocampal ripple oscillation and memory consolidation. Nat Neurosci. 2015;18:728-35.

36. Szonyi A, Mayer MI, Cserep C, Takacs VT, Watanabe M, Freund TF, et al. The ascending median raphe projections are mainly glutamatergic in the mouse forebrain. Brain Struct Funct. 2016;221:735-51.

37. Dao DQ, Perez EE, Teng Y, Dani JA, De Biasi M. Nicotine enhances excitability of medial habenular neurons via facilitation of neurokinin signaling. J Neurosci. 2014;34:4273-84.

38. Ikeda H, Heinke B, Ruscheweyh R, Sandkuhler J. Synaptic plasticity in spinal lamina I projection neurons that mediate hyperalgesia. Science. 2003;299: 1237-40. 